Article

\title{
A Guiding Framework for Levels of Sustainability in Marketing
}

\author{
Alpaslan Kelleci ${ }^{1, *}$ and Oğuz Yıldız ${ }^{2, *(D)}$ \\ 1 Department of Business Administration, Faculty of Economics, Administrative and Social Sciences, \\ Istanbul Gelisim University, Istanbul 34310, Turkey \\ 2 Department of Aviation Management, Faculty of Economics, Administrative and Social Sciences, \\ Istanbul Gelisim University, Istanbul 34310, Turkey \\ * Correspondence: akelleci@gelisim.edu.tr (A.K.); ogyildiz@gelisim.edu.tr (O.Y.)
}

check for

updates

Citation: Kelleci, A.; Yıldız, O. A Guiding Framework for Levels of Sustainability in Marketing. Sustainability 2021, 13, 1644. https:// doi.org/10.3390/su13041644

Received: 19 October 2020

Accepted: 27 January 2021

Published: 4 February 2021

Publisher's Note: MDPI stays neutral with regard to jurisdictional claims in published maps and institutional affiliations.

Copyright: (c) 2021 by the authors. Licensee MDPI, Basel, Switzerland This article is an open access article distributed under the terms and conditions of the Creative Commons Attribution (CC BY) license (https:// creativecommons.org/licenses/by/ $4.0 /)$.

\begin{abstract}
Up to now, far more attention has been paid to assessing the environmental, social, and economic aspects of sustainability. However, what makes this paper distinct is that it proposes a guiding framework that can be employed as a useful tool for business enterprises and other related stakeholders in transforming the potential of marketing disciplines towards upper levels of marketing orientations and sustainable consumption patterns. This present paper follows a typological model that classifies the conceptual approximations that are relatively dispersed in the literature. In doing so, the authors trace back to Kotler's distinction of positive and normative scopes of marketing, then based on this dichotomy, they propose five different sustainability marketing levels and tag them. This paper aims to provide a convenient roadmap for traditional growth-oriented and transitionary firms who are stuck in short-term positive marketing level and thus need to include sustainability and sufficiency as the most prospective options for long term competitive advantage.
\end{abstract}

Keywords: marketing orientation; sustainable marketing; sufficiency marketing; sustainability; sustainable consumption

\section{Introduction}

In a period of great turbulence such as the one we are living in, marketing thought and practice are being constantly shaped by pivotal developments in technology, society, and the environment. Consequently, the marketing discipline has no choice but to adapt itself to such developments and take a transformative approach [1]. Today, organizations have been increasingly challenged by the environmental factors in the form of climate change, such as biodiversity decline, deforestation, collapsing fisheries, and carbon dioxide accumulation in the new epoch, denominated as the Anthropocene [2-4]. Data from several studies suggest that the planet has boundaries, and human demand is likely to be exceeding the regenerative and absorptive capacity of the biosphere [2,5]. Furthermore, after the global outbreak of the coronavirus pandemic in the first quarter of 2020, the world has realized that our topmost responsibility is to restore good health and well-being, which is also advocated by the Sustainability Developments Goals (SDG, Goal 3) of the United Nations [6]. Nevertheless, until the traumatic impact of COVID-19, guidance and recommendations of policymakers were ignored partly because of human beings' negligence and underestimation of the long term, which could be attributed to hyperbolic discounting. It is becoming evident that additional threat to wildlife and the extinction of natural habitats increase the risk of new and more severe outbreaks in the future. Incongruent with such negative externalities, manufacturing, and finance industries have been ruminating on the impact of the aforementioned risks on organizations.

Today, firms are bound to make structural changes and subsequently embrace a sustainable well-being approach contingent on dynamic environmental and market conditions [1]. Under other conditions, those who fail to keep up will lose their competitive edge due to increasing regulatory requirements and social demands [7]. For instance, in parallel 
with increasing regulatory pressures, 17 sustainable development goals of the UNDP were embraced by all countries at the United Nations in September 2015.

In today's "post-modern" time, the developments demonstrate that a mere growthoriented system is unsustainable, and it is inexorably moving towards a devastating collapse. Thus, the dominant paradigm of incessant growth seems to have slipped into a blind alley [8-10].

The traditional growth-oriented or "received marketing paradigm" by and large advocates sheer consumerism that sets forth the acquisition of goods and services in ever-increasing amounts, which results in exploiting natural resources, polluting the environment, and generating waste $[11,12]$. In relation with "received marketing paradigm", marketing has been predominantly "path-dependent" on positive marketing practices and has been under the domain of Dominant Social Paradigm (DSP), which is associated with unsustainability, unsustainable products, and overconsumption [13]; however, today, an "emergent marketing paradigm" in the form of sustainable and sufficiency marketing exposes itself as an immediate alternative marketing system [11].

Sustainability marketing has been studied over the last 30 years, and the literature is rife with various sustainability marketing definitions. There have been also attempts to develop and create sustainability views and frameworks. As in illustration, Neumayer's [14] sustainability typology is the most common framework, which includes the dimensions of weak and strong sustainability, although it has been criticized for its lack of diversity in the sustainability domain. Another typology pertaining to sustainable development is crafted by Hopwood et al. [15], who mapped sustainability as "status quo, reform and transform".

Sustainability and sufficiency are both a part of a sustainable well-being (WB) oriented system; however, they differ from each other. First of all, the term sustainability is a long-established concept. Sustainability's early roots date back to more than 200 years ago. It was first German forestry expert Georg Hartig [16] who described sustainability in 1804 as "utilizing forests to the greatest possible extent, but still in a way that future generations will have as much benefit as the living generation". From a marketing management standpoint, researchers have been studying sustainability marketing over the last 30 years, even though studies are still inadequate. For instance, Purani et al. [17] reviewed 10 of the most highly ranked marketing journals and they discovered that only $2 \%$ of articles were dedicated to sustainability. On the other hand, sufficiency is a relatively new concept, referring to individuals living on needs rather than wants. Sufficiency-based approach was pronounced for the first time in 2006 by the Sustainable Consumption Roundtable [13]. Secondly, while sustainable marketing mostly focuses on product improvements or green products on the supply side, sufficiency marketing nurtures moderate consumption on the demand side, aiming to curb overconsumption by promoting alternative consumption patterns (refurbished, reused, recycled). Finally, while consumers choose sustainability mainly due to extrinsic factors, they adopt sufficiency practices on account of intrinsic factors, as shall be further discussed in Section 4 . Nevertheless, research also demonstrates that even intrinsic behaviors of individuals are shaped by marketing since individuals are a part of the market system [18].

This paper seeks to offer a guiding framework (roadmap) which can be employed as a useful tool for firms and other related stakeholders in transforming the potential of marketing towards upper levels of marketing orientations \& sustainable consumption patterns beyond sustainable production practices.

The present paper follows a typological method that classifies the conceptual approximations that are relatively dispersed in the literature. Typology, a type of research design, contributes through distinguishing, dimensionalizing, or categorizing extant knowledge of the phenomenon, construct, or theory in question [19]. The purpose of this study is to generate a categorization that "explains the fuzzy nature of many subjects by logically and causally combining different constructs into a coherent and explanatory set of types" [20]. Thus, the authors' guiding framework provides both researchers and marketers to analyze 
and categorize existing sustainability marketing applications to develop marketing policies towards sustainable lifestyles and behaviors in terms of creating and delivering value.

This conceptual paper essentially makes contributions to the literature in two different ways. First of all, built upon Philip Kotler's distinction of positive (growth-oriented) and normative (well-being oriented) scopes of marketing [21], it offers a guiding framework, which integrates various marketing orientations. While mass marketing, green marketing, and circular marketing are categorized under the growth-oriented approach; sustainable marketing \& sufficiency marketing are classified under the well-being-oriented approach. Secondly, contrary to Dominant Social Paradigm's consumption patterns and consumer habits, it also considers the substantial impact of "mindful consumers", "downshifters" and Gen Z's role in sustainable consumption patterns [22]. In essence, this roadmap could be a guiding light for traditional organizations in making their way to a sustainable well-being level.

This paper explores a number of bodies of literature. First of all, the authors begin with how growth orientation has been transforming into well-being orientation from the mid-19th century towards the onset of the millennium. Secondly, the authors address the changing concept of value (from value maximization to well-being maximization) in marketing. Finally, a roadmap is proposed for evaluating sustainability from a marketingbased aspect, which is built upon the distinction between positive and normative scopes of marketing (Table 1).

Table 1. Taxonomy of Marketing Based on Kotler's Dichotomy.

\begin{tabular}{|c|c|c|c|c|c|c|c|}
\hline $\begin{array}{c}\text { Kotler's } \\
\text { Dichotomy }\end{array}$ & $\begin{array}{l}\text { Scopes of } \\
\text { Marketing }\end{array}$ & $\begin{array}{l}\text { Consumption } \\
\text { Pattterns }\end{array}$ & $\begin{array}{l}\text { Marketing } \\
\text { Orientations }\end{array}$ & $\begin{array}{c}\text { Marketing } \\
\text { Tools/Platforms Adopted }\end{array}$ & $\begin{array}{c}\text { Waste } \\
\text { Management }\end{array}$ & & $\begin{array}{l}\text { tainability } \\
\text { Level }\end{array}$ \\
\hline \multirow{2}{*}{$\begin{array}{l}\text { Normative } \\
\text { Marketing }\end{array}$} & \multirow{2}{*}{$\begin{array}{l}\text { Sustainable Well- } \\
\text { Being-Oriented }\end{array}$} & $\begin{array}{l}\text { Nominal/Conscious } \\
\text { Consumption }\end{array}$ & $\begin{array}{l}\text { Sufficiency } \\
\text { Marketing }\end{array}$ & $\begin{array}{l}\text { Sharing Platforms via } \\
\text { "Pay-to-use" model }\end{array}$ & Prevention & 5 & Maxi-max \\
\hline & & $\begin{array}{l}\text { Refurbished } \\
\text { Consumption }\end{array}$ & $\begin{array}{l}\text { Sustainable } \\
\text { Marketing }\end{array}$ & $\begin{array}{c}\text { Secondary } \\
\text { MarketingRemarketing }\end{array}$ & Reduction & 4 & Maxi-min \\
\hline \multirow{3}{*}{$\begin{array}{l}\text { Positive } \\
\text { Marketing }\end{array}$} & \multirow{3}{*}{$\begin{array}{l}\text { Traditional } \\
\text { Growth- } \\
\text { Oriented }\end{array}$} & $\begin{array}{c}\text { Recycled } \\
\text { Consumption }\end{array}$ & $\begin{array}{c}\text { Circular } \\
\text { Marketing }\end{array}$ & $\begin{array}{l}\text { Marketing Mix }(4 \mathrm{P}) \text { for } \\
\text { recycled goods }\end{array}$ & Reuse & 3 & Mini-max \\
\hline & & $\begin{array}{l}\text { Green/Organic } \\
\text { Consumption }\end{array}$ & $\begin{array}{c}\text { Green } \\
\text { Marketing }\end{array}$ & $\begin{array}{l}\text { Marketing Mix (4P) for } \\
\text { eco-friendly products }\end{array}$ & $\begin{array}{l}\text { Energy } \\
\text { Recovery }\end{array}$ & 2 & Mini-min \\
\hline & & Mass Consumption & $\begin{array}{c}\text { Mass } \\
\text { Marketing }\end{array}$ & $\begin{array}{l}\text { Marketing Mix }(4 \mathrm{P}) \text { for } \\
\text { traditional products }\end{array}$ & Landfill & 1 & Null \\
\hline
\end{tabular}

Scope of Marketing was adopted from: Hunt, S. D. (2015). Marketing Theory: Foundations, Controversy, Strategy, Resource-Advantage Theory. New York: Routledge. Waste Hierarch was adopted from: Bocken, N., \& Short, S. (2016). Towards a sufficiency-driven business model: Experiences and opportunities. Environmental Innovation and Societal Transitions, 41-61.

\section{Transformation from Growth-Oriented System to Sustainable Well-Being-Oriented System}

We have been witnessing spectacular transformation and flourishing of the world, particularly since the Bretton Woods Conference pertaining to a new world order. Even though significant economic progress was attained, and the living standards of millions of people increased tremendously, millions of other people suffered as a result of negative externalities on the other side of the coin. With respect to the negative externalities, The World Economic Forum (WEF) published the top five risks listed in the Global Risks Report for the first time this year and the risks were associated with the environment and climate change [4]. Capitalism started to have a negative connotation as a result of dubious results it had in different parts of the world. Although economic prosperity is substantially important, the world is now far more interested in how we achieve financial figures.

In the bygone golden days of American management from 1920s to 1960s, American management ruled the world not only in terms of manufacturing, retail and healthcare sectors but also in social awareness and social responsibility of wealth and business [23]. For example, Julius Rosenwald, who was part-owner and leader of Sears, Roebuck and Company, fathered the country farm agent system in the early years of the 20th century. He 
is a social a reformer and a radical innovator. He foresaw that "Sears Roebuck's prosperity depended on the prosperity of its customer, the farmer, which in turn depended on the farmer's skills, productivity, and competence" [23].

Starting from the 1960s, however, things started to go astray. As Milton Friedman in his book Capitalism and Freedom put forward: "the one and only social responsibility of business is to use its resources and engage in activities designed to increase its profits so long as it stays within the rules of the game" [24]. Eventually, material gains were promoted, and individual gains were considered as the ultimate attainment in the domain of shareholder supremacy. Mere pragmatism started to prevail even at the expense of family responsibilities [25]. Income inequality entered into the picture even though it was not discernible in the early 1970s [26], which is now pointed by the Sustainability Developments Goals (SDG, Goal 10) of the United Nations [6]. Unfettered capitalism started to manifest itself in the form of polluted natural resources and soul-draining marketing campaigns. Then again in the 1970s, there was an immense influence of Critical Theory in the study of history, law, literature and social sciences [27]. Critical Theory, as one of the paradigmatic approaches, aimed to overcome the social structures through which people are dominated and oppressed and it made a critique of the prevailing structure without reference to the goal of human emancipation $[28,29]$. In tandem with these developments, it was evident that marketing could not be confined solely into transactional activities, such as buying, selling, and transporting goods and services [30]. One of the most critical shortcomings of the current growth-oriented system has been its inability to define prosperity by focusing only on economic growth. In parallel with the aforementioned social changes in the 1970s, the scope of marketing went beyond downstream marketing to include normative marketing areas, such as social marketing, marketing ethics, societal issues in marketing and the social responsibility of marketing. The concept of marketing scaled up when the Journal of Marketing dedicated an entire issue to marketing's changing social/environmental role in 1971. Kotler and Zaltman [31] used the term "social marketing" for the first time in the same issue of the journal. A positive link between social marketing and well-being is evident. For example, social marketing is an important tool in reducing alcohol consumption, tobacco consumption as well as preventing sexual harassment and thereby increasing the well-being of individuals [13,32]. Also, in connection with socialmarketing and well-being, recent research [33] has demonstrated that a marketing approach to moderate consumption is regarded "as an opportunity to increase individuals' wellbeing through avoiding over-indebtedness" [18]. Furthermore, research has shown that people who lessened their focus on materialism and overconsumption felt happier and more content, which are related to well-being, as shall be explained in Section 4. Today, it has become imperative for business enterprises to develop sustainable behaviors and create sustainable lifestyles not only due to the continuity of firms in the long-term but also for the well-being of society.

Despite the concepts of social marketing and well-being started to enter into the picture in the 1970s, marketing executives continued to put inordinate emphasis on the positive marketing outcomes, such as customer profitability, repeat purchase, re-order and customer retention rates, and etc. The reason for this is that, first of all, it is much easier to measure and compare performance through linear-casual analysis. This strain of thought relies on a reductionist paradigm which tries to explain the whole in terms of its parts. However, we cannot understand the sustainability of the system only by looking at constituents of the system, which is predominantly based on a scientific-industrial framework. Aristotle said that "The whole is greater than the sum of its parts". Lest get this abstract, consider the parable of the blind men and an elephant. It narrates a story of a group of blind men who try to conceptualize the elephant by touching it even though they have never met an elephant before. The parable, out of many interpretations, points to the fact that humans have an inclination to ignore the whole based on their limited experiences.

Secondly, marketing executives have been under pressure by CEOs to perform. Whilst it's good to have a clear goal, marketing practitioners, as well as some marketing aca- 
demicians, got restrained in a narrow domain and the discipline has lost sight of the big picture. Since employees have often been rewarded for short-term performance, they undermined to take measures on longer-term sustainability issues, which might transform the company over a longer time frame [34]. As the saying goes, "When you are up to your neck in alligators, it's hard to remember that your initial objective was to drain the swamp". Indisputably, direct results should have a priority over longer-term results. Nevertheless, as Drucker put forward, "In the care and feeding of an organization, direct results play the role calories play in the nutrition of the human body. But any organization also needs a commitment to values and their constant reaffirmation, as a human body needs vitamins and minerals. There has to be something "this organization stands for," or else it degenerates into disorganization, confusion, and paralysis" [35].

Both unidimensionality and short-termism are an outcome of a regnant economic system which values "pure instrumentality". In respect to the short-termism of commercial marketing, "uncritical marketing" could be coined to describe the fetishistic standpoint of positive marketing in obtaining immediate profit at the expense of squeezing suppliers and employees, baiting customers, and harming the environment. Sadly, uncritical marketing has become an instrument of domination not because of the lack of a multidimensional discourse but because of the dominant powers of a growth-driven system that are able to shape the perceptions and viewpoints of those who do not. In a growth-oriented system, the society's prosperity and growth are primarily based on reification in which materialization, excessive consummation and instant gratification are immensely valued.

A unidimensional prosperity through material success has proved to be successful since the Bretton Woods Agreement in 1944. However, it overlooked ecological and social well-being and ignored shared prosperity. Today, some organizations are shaking off from this "collective blindness" and adopt a transformative approach towards a shared prosperity and collaborative consumption by building innovative platforms, as shall be explained under Sufficiency Marketing-Orientation in the subsequent section of the manuscript.

\section{Transformation of Value in Marketing: From Value Maximization to Well-Being Maximization}

In light of what has been discussed above, marketing discipline has been under the influence of the growth-oriented system and, consequently, in the domain of shareholder supremacy. Eventually, marketing has been constrained into a firm-centric approach, where it primarily focused on the relationship between a firm and its customers, maximizing value in the best interests of the firm. The changing concept of value is discernible in the shifting definition of marketing from 1985 to the present. The American Marketing Association's (AMA) definition of marketing in 1985: "The process of planning and executing the conception, pricing, promotion and distribution of ideas, goods, and services to create exchanges that satisfy individual and organizational goals" [36]. Here, the AMA's 1985 definition of marketing restricted the discipline into a mere organizational role whose boundaries are set within the firm and its customers. Thus, marketing had a segregated and self-contained purpose rather than an integrative commitment to include broader domains and issues.

There were calls for a change in the focus of marketing from a narrow relationship between a firm and its customers to extend the impacts of marketing discipline to a broader relationship to include a host of other actors such as employees, regulators, financiers, and the community at large. Conforming to a call for a new paradigm in 2004, the AMA changed the definition of marketing to pronounce marketing's influence on other organizational stakeholders and not just customers [37]. Following this, a collaborative project between the Aspen Institute's Business and Society Program and Boston University, named the Stakeholder Marketing Consortium, was held in 2007. At the conference, mainstream marketing was questioned, and the influence of marketing on societal welfare was debated. The same year, the AMA expanded this definition to reflect that marketing activities should not only value for specific stakeholder, but for the whole society [38]. Overall, these developments support the view that there has been a growing dissatisfaction with 
mainstream marketing's role among numerous marketing academics. Eventually, the AMA elevated the definition of marketing in 2017 and redefined it as "Marketing is the activity, set of institutions, and processes for creating, communicating, delivering, and exchanging offerings that have value for customers, clients, partners, and society at large" [39].

Besides the above-mentioned transformations in marketing thought, consequential events, such as the Great Recession, climate change, and the yellow vests movements as well as the soul-draining practices of positive marketing demonstrated that marketing discipline has a duty to transform itself beyond dominant positivist managerial epistemology. Polonsky et al.'s [40] "harm chain" acknowledges how transactional activities result in the generation of harm. Today, the "received marketing paradigm" is in the grip of disintegration since laisses-faire capitalism no longer seems to be sustainable [11]. The concept of value is challenged with the adverse developments and concerns on social and economic crises that are transforming the very idea of value itself. The business trajectory is towards a more human-centric future that will redesign people's lifestyles [41]. Escalating social and environmental problems are requiring profound changes in the scope of marketing from positive to normative. This more human-centric normative approach has two outcomes for businesses. First of all, incumbent companies are required to adapt themselves to a new paradigm shift and seek to propose innovative well-being solutions on the market, inclusive of people, society, and the environment. Secondly, a new type of company is flourishing in tandem with the value transformation. Novel type of socially-led companies, a.k.a. "Social Sector Organizations" (SSO) [42,43], have been dealing with social problems and introducing new social solutions. En route towards a more human-centric future, social models and more human ways of creating value are transforming, and innovative business models, novel networks, and new partnerships are being formed for the industries of the future.

Today, corporations need sustainability not just as a public relations strategy to pacify stakeholders or to obtain credibility from them and improve community relations. There are other reasons why sustainability should be incorporated into the business strategy. First of all, sustainability is a stimulating force to boost a firm's financial performance through increased sales due to improved corporate reputation and contracted regulatory non-compliance costs. Secondly, some corporate leaders have engaged in sustainability due to social and moral grounds. Leaders recognize the link between business and society and rethink their economic, environmental, and social responsibilities around the concept of sustainability [44]. (Epstein \& Buhovac, 2014).

In connection with the shift from value maximization to well-being maximization, Busines Round Table's (BRT) announcement further reinforced the transformation of marketing value towards sustainability-orientation. BRT's announcement in August 2019 redefined the purpose of a corporation to promote "An Economy That Serves All Americans" [45]. The new statement was signed by 181 CEOs, whose members are CEOs of major U.S. companies such as Tim Cook of Apple and Arvind Krishna of IBM Corporation. BRT has already been regularly issuing the Principle of Corporate Governance since 1978. The release of the new statement on the Purpose of Corporation in 2019 by BRT seems to herald a new reversion to the status quo ante of "golden age of American management", from shareholder maximization to well-being maximization and may even imply a shift from democratic capitalism to socialist capitalism.

\section{A Proposed Framework for Sustainability Level in Marketing}

Philip Kotler classified marketing phenomena using the concepts micro, macro, normative, and positive during a presentation at the 1972 fall conference of the American Marketing Association [21]. Building upon the distinction between positive and normative scopes of marketing, the authors initially categorized scopes of marketing as growthoriented (traditional) and well-being-oriented (sustainable) and then respectively classified consumer patterns, marketing orientations, marketing tools adopted, and waste manage- 
ment practices. Then, drawing on this typology, the authors scaled the sustainability levels of organizations from a marketing standpoint (Table 1).

As can be seen from Table 1, positive marketing is inherently growth-oriented and includes three levels of marketing-orientations: mass-marketing, green marketing, and circular marketing. By contrast, normative marketing is sustainable well-being-oriented and consists of two levels of marketing-orientations: sustainable marketing and sufficiency marketing.

At Level 1, marketers predominantly seek to fulfill the unmet needs of large segments of customers. At this basic level, markets are flourishing fast, and markets have a tendency to expand since the majority of such markets are described as nascent markets. In the developed world, such nascent markets no longer exist on account of the fact that the U.S., Europe, and Japan reached their full limits. Marketers seeking such nascent markets seek to satisfy the unfulfilled needs of developing markets, particularly in the key bottom of the pyramid (BoP) markets, i.e., Nigeria, China, South Africa [46]. The key BoP markets have not reached a contraction stage yet as they still have significant unmet needs.

Mass-marketing orientation exists in traditional growth-oriented markets, which has been prevalent since the late Industrial Revolution in the late 18th century [47]. Today, organizations with pure mass-marketing activities are the least desirable business entities since goods are manufactured and consumed on a massive scale and are usually disposed through landfilling or incineration. Resources are lost, and there is little or no consideration for social and environmental issues from a sustainability point of view. Companies, at this level, are considered in the most primal marketing stage without self-sustaining practices. Thus, the authors propose that companies with a mass-marketing orientation, at this basic stage, should be considered at "null" sustainability level.

At Level 2, marketers aim to lure socially, and environmentally conscious customers since organizations have become cognizant that corporate social responsibility (CSR) initiatives are positively linked with corporate reputation, customer loyalty, and purchase intentions. However, green marketing is still a continuation of the growth-driven stage. Previous research has indicated that images of nature-evoking ads can influence consumers' evaluations of ads and brands by inducing an emotional response akin to feelings experienced from actual contact with nature [48]. Since such "virtual nature experiences" can have a positive impact on the consumer persuasion process, green marketing can be considered as a part of reactive market-orientation to exploit consumers. Organizations are devoid of proactive market-orientation since green marketing efforts are still at a reactive level to appease stakeholders. The real motivation behind green marketing is to differentiate from the rest of the market and sell more eco-friendly products for green-sensitive customer segments. As Achrol and Kotler [11] put forward: "marketing has taken a passive and reactive position vis-à-vis sustainability- by developing 'alternatives' (often perceived as more expensive and less effective)". Companies at this stage are substantially concerned about reputational interests and the political and social activities to tackle market challenges [49]. Furthermore, at this stage, marketing is associated with "greenwashing" or "cosmetic" rhetoric and cosmetic efforts are perceived as hypocritic by consumers [50]. Thus, society in general and green consumers, in particular, are questioning the genuineness of green marketing activities, particularly after the Volkswagen scandal in 2015. In addition, research has demonstrated that "green buying", in reality, offers a way for materialists to fulfill their desire to accumulate new items [51]. For this reason, green marketing appears as a pretense alternative for continued consumption to satisfy the extrinsic goals of individual consumers or to have recognition from other stakeholders [52].

In light of what has been discussed above, the authors propose that organizations with green marketing activities at this elementary stage should be considered at "minimin" sustainability level since a continuum of states exists between pure economic and societal activities.

At Level 3, marketers focus on selling more re-usable products by targeting ecofriendly customers. They mainly concentrate on efficiency and productivity improvements 
in reducing the impacts of production and consumption, as in the case of Apple's 100 percent recycled aluminum products. The principles of the circular economy are established on the production philosophies of Toyota since the mid-1940s [47]. In a circular economy, resources are circulated continually through closed loops. Consequently, the useful life of materials is prolonged through recycling and re-use. Nevertheless, recycling, as in the case of green marketing, is still considered as a continuum of the traditional growth-oriented system since it still promotes a consumption-led growth based on material re-use. As an illustration, recycling stimulates rebound-effects, where efficiency gains induce more consumption [53,54]. In other words, even though materials are recycled and reused to curb demand for new materials, the motive to urge consumers to have more goods is not diminished. In addition to the rebound effects, recycling processes require a considerable amount of energy, and the process of doing so results in negative environmental externalities as a result of harmful consequences such as the release of toxins or greenhouse gases and consequently the warming of the climate. As Allwood [55] put forward: "if demand is growing, the circle cannot remain closed, and it may be a much more important priority to reduce the rate at which new material is required. If today's products require precise and complex mixing of atoms to create high-performance properties, the energy required to separate them from these products may be very much greater than the energy required to extract new material from ore or tailings". For this reason, circular marketing is still considered among the lower orders of a hierarchy of options for reducing negative impacts only to some extent.

In view of what has been discussed above, circular marketing is still not an enlightened approach, although it is considered more sophisticated than Level 1 and 2. For this reason, circularity could not be the ultimate goal for an enlightened company to achieve a higher quality of life for all stakeholders. Therefore, unless the global demand for both the volume and composition of products is not stabilized, it is hard to achieve an authentic progression in the quality of life. Thus, the authors propose that organizations with circular marketing activities should be considered at "mini-max" sustainability level.

At Level 4, marketers need a paradigmatic change of mindset in marketing activities since customers have a new level of consciousness towards consumption due to the dramatic changes in the environment and particularly in the economy, i.e., the Great Recession in 2008-2009. For example, the traumatic impact of COVID-19 prompted a drastic shift towards an awakening of consciousness among all citizens. Householders have a conscious thought of their buying acts and consumption habits for the reason that every consumption has an ecological cost. Change at this stage, though, is still predominantly from "outside-in" and is not a society-wide evolution that people have started to question prevailing economic structures, which focus on downstream marketing activities or consumerist lifestyles. Sustainable marketing-orientation is a less progressive version of sufficiency marketing-orientation since companies consider the shrinking purchasing power of consumers as a marketing opportunity to craft secondary or refurbished goods markets. For instance, at this level, secondary markets appear as a solid alternative for consumer electronics, as in the case of Apple Certified Refurbished and Amazon Renewed.

According to a survey by Liquidity Services in 2014, "Refurbished products are readily accepted as an option for electronics; $75 \%$ of survey respondents say they are likely to buy refurbished electronics and $94 \%$ state they have bought refurbished in the last three years" [56]. Over the last few years, the resale industry has generated billions of dollars in the USA [57]. As a consequence of the huge potential of the second-hand market as well as declining sales of new smartphones, Apple made a strategy change, and it relies increasingly on refurbished iPhones for new revenue creation. Furthermore, Apple embraces a refurbished business model on the grounds that it will be distinguished as an environmentally conscious company [58].

In addition to the rise of refurbished electronics, the second-hand apparel market has been skyrocketing. According to ThredUp's 2019 Resale Report, "the second-hand apparel market has been growing 21 times faster than retail apparel over the last three 
years and is on track to be larger than fast fashion by 2028" [59]. ThredUp explains this sharp growth in the resale sector owing to the fact ecological sustainability trend is surging among consumers, particularly among young consumers, such as millennials or Gen Z. As maintained by ThredUp's 2019 Resale Report, 51\% of consumers plan to spend more on secondhand in the next 5 years [60]. Furthermore, according to McKinsey's The State of Fashion 2019 Report, "the number of brands getting into the rental, resale, and refurbishment business will increase markedly" [61] and "more consumers will see a growing proportion of their wardrobes made up of pre-owned or rented products, especially for high-value items and accessories" [61]. Companies pursuing marketing activities in second-hand markets should focus on resale value.

Even though reusing items reduces waste dramatically and consequently, less new materials are sent to landfills or waste combustion facilities, the rise of resale markets, on the other side of the coin, stimulated consumption of used clothing and vintage fashion over the last 10 years [62]. For instance, the vintage trend has been gaining further momentum in Brazil, and the number of thrift stores went up by 22 percent in 2015 [63]. Thus, the real motive here may not be environmental or sustainability concerns but appears to be style and uniqueness for style-conscious consumers. In connection with the previously mentioned studies, ref. [64] Scitovsky also argued that second-hand markets for consumer durables "stimulate the economy partly by enabling the well-to-do the sooner to replace their worn-out or obsolescing durable goods with new ones and thereby increasing the total demand for them". This implies that second-hand markets may actually increase material consumption rather than decrease it.

The authors propose that organizations with sustainable marketing activities should be considered at the "maxi-min" sustainability level, depending on the resale value of their products. For example, Patagonia's winter coats, Everlane's sweaters, Kate Spade's leather backpacks, Madewell's leather crossbody bags, Frye's leather boots, and Diane Von Furstenberg's jumpsuits are known to have the best resale value in their category in the fashion industry [60].

At Level 5, marketers need to innovate novel ways to appease consumption-conscious customers who seek to minimize the unnecessary consumption of material goods and the pursuit of wealth for its own sake because of emerging lifestyle choices, such as "downshifting" or "simple living" [65]. "Downshifting" is a collective reframing of mindset to overcome the social structures through which people are dominated. It transcends beyond traditional social norms towards a simpler, leaner, and collaborative lifestyle for real human emancipation. In other words, the change towards conscious consumption is initiated intrinsically, in customers' own discretion as opposed to sustainable marketing, where the change is triggered by extrinsic factors, such as an economic or environmental crisis. It appears that the tide is turning against the acquisition of material accumulation and consumption. For example, according to GlobalData, even before the outbreak of COVID-19, nearly $20 \%(19.2 \%)$ of consumers have been consciously modifying their behavior, and they have been planning to spend less than usual in 2020. As nearly half $(48.9 \%)$ of these consumers were making conscious efforts to buy less stuff, they were seen as the biggest threat to clothing and footwear retailers in North America and Europe [66].

Recent research has suggested that voluntary simplifiers feel happier and more content than consumers [67]. Current shifts in consumer behavior require firms to embrace more society-centric and normative approaches. For example, Ballantine and Creery's [5] study on 12 voluntary simplifiers has demonstrated that participants have shown an intense inclination for shared ownership rather than individual possession for certain items. Participants, where possible, preferred the benefits of shared ownership, which stressed their lessened focus on materialism. Kemper and Ballentine [13] put forward that "Consumers are strongly recognized as leaders for change, and thus, consumer demand is seen as a reason to engage in sustainable activities". Therefore, today, firms who are advocating collaborative consumption through "pay-to-use" revenue models are said to be much more proactive and enlightened in today's new sharing economy. Such firms are also concerned 
about eliminating billions of dollars in waste through these sharing platforms. Companies, such as Rent the Runway, in addition to the well-known Uber and Airbnb, employ "pay-to-use" revenue models instead of the traditional "pay-to-own" revenue models. For example, the German company Winterhalter has been in the commercial dishwasher industry since 1947. The company has started to employ a subscription-based revenue model, which is built on "Pay per Wash" system instead of merely selling dishwashers, racks, and detergents. Subscribers benefit from this system since they make no investment and take no risk as in the traditional ownership model. The customer chooses a preconfigured washing program and enters the number of wash cycles through the Pay per Wash portal, and starts the machine [68]. Thus, the customers pay for the end results rather than the means. Likewise, Teatreneu is a company in the entertainment industry in Barcelona, Spain. The country's small theatres started to struggle with financial difficulties when the Spanish government increased the tax rate from $8 \%$ to $21 \%$ in 2013 . To struggle with the falling audience numbers, the company implemented an exceptional system which allowed it to track how much spectators enjoyed the show. A facial recognition system mounted on the back of the seat registered spectators' laughter and charged them per laugh. Each laugh was charged at a rate of 30 Euro cents, with a maximum charge set at 24 Euros [69].

In light of what has been said above, sufficiency marketing-orientation appears as the most sustainable approach from a marketing standpoint since it seeks to eliminate consumption and material waste through "pay-to-use" revenue models by creating digital collaborative consumption platforms, which enable to fulfill real needs rather than means. Thus, the authors propose that organizations with such practices should be considered at "maxi-max" sustainability level.

\section{Conclusions and Implications}

This paper seeks to offer a roadmap which can be employed as a useful tool for business enterprises, academia, and other related stakeholders in transforming the potential of marketing towards upper levels of marketing orientations \& consumption patterns beyond sustainable production practices.

The guiding framework (Table 1) is also a good conceptual tool in dimensionalizing or categorizing sustainability marketing as opposed to Dominant Social Paradigm's categorization where green marketing has been classified under sustainability marketing. Sustainability marketing in practice is largely associated with product characteristics (eco-efficient and green products), production conditions or green marketing practices. Nevertheless, the authors consider such approaches as a continuum of positive or traditional growth-oriented marketing, which seeks to strengthen the sustainable image of the company, particularly for profit-driven reasons, since such practices promote growth through more consumption in alternative ways.

This study also suggests a guideline for traditional growth-oriented firms who have a desire to embark on a sustainability journey and sustainable ways of doing business so as to have a competitive edge. Traditional growth-oriented practices of firms with positive marketing practices have been getting antiquated as a result of dramatic shifts in environmental and ecological degradations as well as the changing social norms (dematerialization, simple living, voluntary simplifying) and consumption habits (refurbished consumption, conscious consumption).

Business enterprises should factor in radical structural changes in both the environment and the society and need to move from traditional growth-oriented level to sustainable WB-oriented level, which incorporates both sustainability and sufficiency. A sustainable WB-oriented system, in general, promotes abstinence and denial of overconsumption and is concerned about the negative impacts of positive marketing due to the ever-increasing consciousness of downshifters, voluntary simplifiers, and mindful consumers. The ideal concept of sustainable WB-oriented system incorporates consumer rejection of linear production systems and traditional product chains [12]. 
In relation with the emerging concept of well-being, today's normative marketing requires new business models and a transformation of organizational consciousness in meeting the needs and wants of the newly rising consumer segments. Previous studies have reported that a traditional growth-oriented positive marketing mindset does not seem tenable for a sustainable future since there is a fundamental transformation in the purpose of business [54,70,71].

In parallel with structural changes and radical transformations which are mentioned above, business enterprises at the foundational level of the proposed framework or transitional levels of sustainability (mini-min \& mini-max) should consider the below mentioned practical recommendations:

First of all, today, the value concept is shifting from value maximization to well-being (WB) maximization. As discussed in Section 3, a new type of company is flourishing consistent with this value transformation. These new types of companies are known as Social Sector Organizations (SSO) who have been dealing with social problems and introducing new social solutions. These new SSOs seek to introduce innovative well-being solutions on the market, inclusive of people, society, and the environment.

Secondly, in connection with the value transformation, firms should switch from a traditional ownership business model (pay-to-have) to a more inclusive and all-embracing "pay-to-use" business model. Reinforcing the case of Wintherhalter in Section 4, Rent the Runway offers women to choose from a wide selection of dresses, handbags, accessories and designer clothes by renting instead of buying. As maintained by the company's cofounder and CEO Jennifer Hyman, Rent the Runway's goal is "to create the Amazon Prime of rental". Women have the opportunity to select clothes and accessories online and even seeing how they look by checking photos posted by previous users.

Thirdly, firms should focus on creating products with a strong resale value. For example, Apple phones generally hold the most resale value on the used market- at least during those first three years of ownership [72]. Similarly, in the automotive industry, Toyota vehicles carry their value across all vehicle segments as they depreciate only $42.3 \%$ on average after five years of ownership, while the overall average in the industry is $49.6 \%$ [73]. In reassuring buyers to buy refurbished, firms can create their own secondary markets rather than marketplaces like eBay so that consumers can know the quality of goods they are buying. That being so, firms who created their own secondary markets would draw a clear line between goods that have been used and those that have been professionally refurbished.

Far-sighted companies with a proactive market-orientation have already started to take customers' changing preferences towards dematerialization since research has demonstrated that certain social groups, such as downshifters and voluntary simplifiers have shown intense inclination to live sustainably. Nevertheless, environmentally and socially sustainable practices are not shared by the larger part in most societies or cultures. New ownership models such as shared ownership, second-hand ownership, and refurbished ownership are still not valued and embraced predominantly in most cultures.

From an academic standpoint, the above-mentioned changes require new thinking by governments, business enterprises, academia, and other related stakeholders at the systemic level as a whole. At this point, however, the marketing discipline is in an immediate position to initiate change as it has the means to bring about radical transformations in consumption patterns. It is marketing's responsibility to foster sustainable behavioral changes and sustainable lifestyles. Dominant consumption patterns are not sustainable until a mainstream culture of sustainability and new ways of creating and delivering value is forged by the marketing discipline. The duty notably falls to marketing to engender macro-culture-level changes in society's awareness and values regarding sustainability and sustainable consumption patterns. 


\section{Limitations}

Tackling sustainability requires a broader perspective from economic, ecological, and social aspects. Nevertheless, this paper focuses on evaluating sustainability from a marketing standpoint as it only deals with sustainability and sufficiency based on consumption patterns and marketing orientations within the prevailing literature. Therefore, future research should take into account further dimensions of sustainability marketing, which incorporates ecological marketing mix coupled with sustainable value creation \& delivery, and value capture.

Author Contributions: Conceptualization, A.K.; methodology, A.K., O.Y.; software, A.K., O.Y.; validation, A.K., O.Y.; formal analysis, A.K., O.Y.; investigation, A.K., O.Y.; resources, A.K., O.Y.; data curation, A.K., O.Y.; writing-original draft preparation, A.K.; writing-review and editing, A.K., O.Y.; visualization, A.K.; supervision, A.K., O.Y.; project administration, A.K.; funding acquisition, A.K., O.Y. All authors have read and agreed to the published version of the manuscript.

Funding: This research received no external funding.

Institutional Review Board Statement: Not applicable.

Informed Consent Statement: Not applicable.

Data Availability Statement: No new data were created or analyzed in this study. Data sharing is not applicable to this article.

Conflicts of Interest: The authors declare no conflict of interest.

\section{References}

1. Kumar, V. Transformative Marketing: The Next 20 Years. J. Mark. 2018, 82, 1-12. [CrossRef]

2. Borucke, M.; Moore, D.; Cranston, G.; Gracey, K.; Iha, K.; Larson, J.; Lazarus, E.; Morales, J.C.; Wackernagel, M.; Galli, A. Accounting for demand and supply of the biosphere's regenerative capacity: The National Footprint Accounts' underlying methodology and framework. Ecol. Indic. 2013, 24, 518-533. [CrossRef]

3. World Economic Forum. The Global Risks Report 2020; World Economic Forum: Geneva, Switzerland, 2020.

4. World Economic Forum. What COVID-19 Tells Us about the Changing Nature of Disaster Risk. World Economic Forum. Available online: https:/ / www.weforum.org/agenda/2020/04/here-are-the-biggest-risks-we-re-facing-right-now-the-covid-19-crisisreveals-how-to-stop-them/ (accessed on 5 August 2020).

5. Ballantine, P.W.; Creery, S. The consumption and disposition behaviour of voluntary simplifier. J. Consum. Behav. 2010, 9, 45-56. [CrossRef]

6. UNDP. UNDP in Turkey. Sustainable Development Goals. Available online: https://www.tr.undp.org/content/turkey/en/ home/sustainable-development-goals.html (accessed on 27 September 2020).

7. Berrone, P. Green Lies: How Greenwashing Can Destroy a Company (and How to go Green without the Wash); Kindle: Amazon; Createspace Independent Publishing Platform: Scotts Valley, CA, USA, 2016.

8. Latouche, S. Farewell to Growth; Polity Press: Cambridge, UK, 2009.

9. Gordon, R.; Carrigan, M.; Hastings, G. A framework for sustainable marketing. Mark. Theory 2011, 11, 143-163. [CrossRef]

10. The British Academy. Reforming Business for the 21st Century: A Framework for the Future of the Corporation; The British Academy: London, UK, 2018.

11. Achrol, R.S.; Kotler, P. Frontiers of the marketing paradigm in the third millennium. J. Acad. Mark. Sci. 2012, 40, 35-52. [CrossRef]

12. Bocken, N.; Short, S. Towards a sufficiency-driven business model: Experiences and opportunities. Environ. Innov. Soc. Transit. 2016, 18, 41-61. [CrossRef]

13. Kemper, J.A.; Ballantine, P.W. What do we mean by sustainability marketing? J. Mark. Manag. 2019, 35, 277-309. [CrossRef]

14. Neumayer, E. Weak Versus Strong Sustainability: Exploring the Limits of Two Opposing Paradigms; Edward Elgar Publishing: Cheltenham, PA, USA, 1999.

15. Hopwood, B.; Mellor, M.; O’Brien, G. Sustainable development: Mapping different approaches. Sustain. Dev. 2005, 13, 38-52. [CrossRef]

16. Georg Ludwig Hartig, G.F. Forst-Und Jagd-Archiv Von Und Für Preussen, 1816; Forgotten Books: London, UK, 2018 ; Volume 1.

17. Purani, K.; Sahadev, S.; Kumar, D.S. Globalization and academic research: The case of sustainability marketing. IIM Kozhikode Soc. Manag. Rev. 2014, 3, 93-99. [CrossRef]

18. Gossen, M.; Ziesemer, F.; Schrader, U. Why and How Commercial Marketing Should Promote Sufficient Consumption: A Systematic Literature Review. J. Macromark. 2019, 39, 252-269. [CrossRef]

19. Macinnis, D.J. A Framework for Conceptual Contributions in Marketing. J. Mark. 2011, 75, 136-154. [CrossRef] 
20. Cornelissen, J. Editor's comments: Developing propositions, a process model, or a typology? Addressing the challenges of writing theory without a boilerplate. Acad. Manag. Rev. 2017, 42, 1-9. [CrossRef]

21. Hunt, S.D. Marketing Theory: Foundations, Controversy, Strategy, Resource-Advantage Theory; Routledge: New York, NY, USA, 2015.

22. Koch, L. eMarketer. D2C Brands Attract Young Consumers with Sustainability Initiatives. Available online: https://www. emarketer.com/content/d2c-brands-attract-young-consumers-with-sustainability-initiatives (accessed on 27 September 2020).

23. Drucker, P.F. The New Meaning of Corporate Social Responsibility. Calif. Manag. Rev. 1984, 26, 53-63. [CrossRef]

24. Friedman, M. Capitalism and Freedom; The University of Chicago: Chicago, IL, USA, 1982.

25. Drucker, P.F. The Concept of the Corporation; Routledge Taylor \& Francis Group: London, UK; New York, NY, USA, 1993.

26. DeNavas-Walt, C.; Proctor, B.D. Income and Poverty in the United States: 2014; United States Census Bureau: Washington, DC, USA, 2014.

27. Encyclopædia Britannica. Britannica. Critical Theory. Available online: https://www.britannica.com/topic/critical-theory (accessed on 8 August 2020).

28. Marcuse, H. One-Dimensional Man; Routledge \& Kegan Paul: London, UK, 1964.

29. Best, B.; Bonefeld, W.; O'Kane, C. Introduction: Key Texts and Contributions to a Critical Theory of Society. In The SAGE Handbook of Frankfurt School Critical Thoery; Best, B., Bonefeld, W., O'Kane, C., Eds.; Sage Publications Ltd.: Los Angeles, CA, USA; London, UK; New Delhi, India; Washington, DC, USA; Melbourne, Australia, 2018; pp. 1-17.

30. Lavidge, R.J. The Growing Responsibilities of Marketing. J. Mark. 1970, 34, 25-28. [CrossRef]

31. Kotler, P.; Zatlman, G. Social Marketing: An Approach to Planned Social Change. J. Mark. 1971, 35, 3-12. [CrossRef] [PubMed]

32. Bhat, S.A.; Darzi, M.A.; Hakim, I.A. Understanding Social Marketing and Well-being: A Review of Selective Databases. J. Decis. Mak. 2019, 44, 75-87. [CrossRef]

33. Seegebarth, B.; Peyer, M.; Balderjahn, I.; Wiedmann, K.P. The Sustainability Roots of Anticonsumption Lifestyles and Initial Insights Regarding Their Effects on Consu-mers' Well-Being. J. Consum. Aff. 2016, 50, 68-99. [CrossRef]

34. Graham, J.; Harvey, C.; Rajgopal, S. The Economic Implications of Corporate Financial Reporting. J. Account. Econ. 2005, 40, 3-73. [CrossRef]

35. Drucker, P. The Essential Drucker; Kindle Edition; HarperCollins e-books: Sydney, Australia; Toronto, ON, Canada; Rosedale, ON, Canada; London, UK; New York, NY, USA, 2001.

36. Gundlach, G.T.; Wilkie, W.L. The American Marketing Association's New Definition of Marketing: Perspective and Commentary on the 2007 Revision. J. Public Policy Mark. 2009, 28, 259-264. [CrossRef]

37. Brønn, P.S. Marketing and Corporate Social Responsibility. In The Handbook of Communication and Corporate Social Responsibility; Ihlen, Ø., Bartlett, J.L., May, S., Eds.; ePDF: Wiley-Blackwell: Hoboken, NJ, USA, 2011; pp. 110-127.

38. Ringold, D.J.; Weitz, B. The American Marketing Association Definition of Marketing: Moving from Lagging to Leading Indicator. J. Public Policy Mark. 2007, 26, 251-260. [CrossRef]

39. AMA. The Definition of Marketing. American Marketing Association. Available online: https://www.ama.org/the-definition-ofmarketing-what-is-marketing/ (accessed on 9 May 2020).

40. Polonsky, M.J.; Carlson, L.; Fry, M.-L. The harm chain: A public policy development and stakeholder perspective. Mark. Theory 2003, 3, 345-364. [CrossRef]

41. Cetindamar, D.; Phaal, R.; Probert, D. Technology Management: Activities and Tools; Palgrave: London, UK, 2016.

42. Morgan, R. Calculating Social Value; The Leverhulme Centre for the Study of Value School of Environment, Education and Development: Manchester, UK, 2015.

43. Johnston, L. More Beauty Brands Jump on Hand Sanitizer Bandwagon to Fight COVID-19. Available online: https: // consumergoods.com/more-beauty-brands-jump-hand-sanitizer-bandwagon-fight-covid-19 (accessed on 23 April 2020).

44. Epstein, M.J.; Buhovac, A.R. Making Sustainability Work: Best Practices in Managing and Measuring Corporate Social, Environmental, and Economic Impacts; Greenleaf Publishing Limited: San Francisco, CA, USA, 2014.

45. Business Roundtable. Business Roundtable. Business Roundtable Redefines the Purpose of a Corporation to Promote 'An Economy That Serves All Americans'. Available online: https:/ / www.businessroundtable.org/business-roundtable-redefinesthe-purpose-of-a-corporation-to-promote-an-economy-that-serves-all-americans (accessed on 18 September 2020).

46. Hodgson, A. Top 5 Bottom of the Pyramid Markets: Diverse Spending Patterns and Future Potential. Euromonitor International. Available online: https:/ / blog.euromonitor.com/top-5-bottom-pyramid-markets-diverse-spending-patterns-future-potential/ (accessed on 14 August 2020).

47. The Danish Environmental Protection Agency. Best Practice Examples of Circular Business Models; The Danish Environmental Protection Agency: Copenhagen, Denmark, 2016.

48. Hartmann, P.; Apaolaza-Ibáñez, V. Green advertising revisited: Conditioning virtual nature experiences. Int. J. Advert. 2009, 28, 715-739. [CrossRef]

49. Mantere, S.; Pajunen, K.; Lamberg, J.-A. Vices and Virtues of Corporate Political Activity. Bus. Soc. 2009, 48, 105-132. [CrossRef]

50. Shim, K.; Kim, J.-N. The Impacts of Ethical Philosophy on Corporate Hypocrisy Perception and Communication Intentions Toward CSR. Int. J. Bus. Commun. 2017, 1-24. [CrossRef]

51. Helm, S.; Serido, J.; Ahn, S.Y.; Ligon, V.; Shim, S. Materialist values, financial and pro-environmental behaviors, and well-being Young Consum. 2019, 20, 264-284. [CrossRef] 
52. Kasser, T.; Ryan, R.M. Further Examining the American Dream: Differential Correlates of Intrinsic and Extrinsic Goals. Personal. Soc. Psychol. Bull. 1996, 22, 280-287. [CrossRef]

53. Druckman, A.; Chitnis, M.; Sorrell, S.; Jackson, T. Missing carbon reductions? Exploring rebound and backfire effects in UK households. Energy Policy 2011, 39, 3572-3581. [CrossRef]

54. Bocken, N.; Short, S.; Rana, P.; Evans, S. A literature and practice review to develop sustainable business modelarchetypes. J. Clean. Prod. 2014, 65, 42-56. [CrossRef]

55. Allwood, J.M. Squaring the Circular Economy: The Role of Recycling within a Hierarchy of Material Management Strategies. In Handbook of Recycling: State-of-the-Art for Practitioners Analysts, and Scientists; Worrell, E., Reuter, M.A., Eds.; Elsevier: Amsterdam, The Netherlands, 2014; pp. 445-477.

56. Rallo, J. The Rise of Refurbished Products. Liquidity Services. Available online: https://www.liquidityservices.com/the-rise-ofthe-refurbished-goods-market/ (accessed on 6 October 2020).

57. United States Census Bureau. United States Census Bureau. National Thrift Store Day: 17 August 2018. Available online: https:/ / www.census.gov/newsroom/stories/2018/thrift-store.html (accessed on 8 August 2020).

58. Vaute, V. Forbes. Refurbished Is the Future (For the World, but Also for Tim Cook). Available online: https://www.forbes.com/ sites/vianneyvaute/2019/10/01/refurbished-is-the-future-for-the-world-but-also-for-tim-cook/\#50c1b1013d52 (accessed on 8 August 2020).

59. Luxiders. Second Hand Is on the Move: Increasing Sales as Never Before. Available online: https://luxiders.com/second-handmarket-2018/ (accessed on 8 August 2020).

60. ThredUp. 2019 Resale Report; Digital-PDF: Oakland, CA, USA, 2019.

61. McKinsey \& Company. The State of Fashion 2019; The Business of Fashion McKinsey \& Company: London, UK, 2019.

62. Cervellon, M.-C.; Carey, L.; Harms, T. Something old, something used: Determinants of women's purchase of vintage fashion vs second-hand fashion. Int. J. Retail Distrib. Manag. 2012, 40, 956-974. [CrossRef]

63. Machado, M.A.; Ordovás de Almeida, S.; Bollick, L.C.; Bragagnolo, G. Second-hand fashion market: Consumer role in circular economy. J. Fash. Mark. Manag. 2019, 23, 382-395. [CrossRef]

64. Scitovsky, T. Towards a Theory of Second-hand Markets. Kyklos 1994, 47, 33-52. [CrossRef]

65. Brown, H.S.; Vergragt, P.J. From consumerism to wellbeing: Toward a cultural transition? J. Clean. Prod. 2016, 132, 308-317. [CrossRef]

66. Valentine, M. MarketingWeek. Conscious Consumerism: How Brands Are Rising to the Challenge. Available online: https: / / www.marketingweek.com/conscious-consumerism-brand-challenge/ (accessed on 1 October 2020).

67. Walther, C.S.; Sandlin, J.A.; Wuensch, K. Voluntary Simplifiers, Spirituality, and Happiness. Humanit. Soc. 2016, 40, 22-42. [CrossRef]

68. Winterhalter. No Investment, Zero Risk, Pay Per Wash. Pay-Per-Wash. Available online: http://www.pay-per-wash.biz/uk_en/ (accessed on 13 September 2020).

69. Culzac, N. The Comedy Club Using Facial Recognition Software to Charge Per Laugh, Not Per Show. Independent. Available online: https:/ / www.independent.co.uk/life-style/gadgets-and-tech/news/the-comedy-club-using-facial-recognitionsoftware-to-charge-per-laugh-not-per-show-9785646.html (accessed on 13 September 2020).

70. Jackson, T. Prosperity without Growth: Economics for a Finite Planet; Earthscan Publishing for a Sustainable Future: London, UK; Sterling, VA, USA, 2009.

71. Ehrenfeld, J.R.; Hoffman, A.J. FLOURISHING: A Frank Conversation About Sustainability; Stanford University Press: Palo Alto, CA, USA, 2013; p. 14.

72. Verduzco, W. Apple iPhone vs Samsung Galaxy S: Which Phones Have the Best Resale Value? Swappa Blog. Available online: https:/ / swappa.com/blog/apple-iphone-samsung-galaxy-resale-value/\#: :text=Regardless $\% 20$ of $\% 20$ the $\% 20$ storage $\%$ 20configuration, high\%2Dend\%2C\%20flagship\%20devices (accessed on 5 September 2020).

73. Chang, B. These 10 Car Brands' Vehicles Have the Best Resale Value, According to the Data. Business Insider. Available online: https:/ / www.businessinsider.com/10-car-brands-with-the-best-resale-value-2019-11 (accessed on 5 September 2020). 